\title{
Acoustic insulation properties of lime mortars with natural lightweight aggregate
}

\author{
Martin Vyšvařil ${ }^{1, *}$, Libor Topolár ${ }^{1}$, and Richard Dvořák ${ }^{1}$ \\ ${ }^{1}$ Brno University of Technology, Faculty of Civil Engineering, Veveři 331/95, 60200 Brno, Czech \\ Republic,
}

\begin{abstract}
Porous pozzolan-active aggregate can be used to prepare lightweight lime mortars with high ability to salt accumulation from masonry, enhanced strengths and improved their acoustic and thermal insulation properties, or fire resistance. In this study, the effect of 3 types of natural lightweight aggregate on acoustic insulation properties of air lime mortars, NHL mortars, and cement-lime mortars has been investigated. Measurements of the signal attenuation in the frequency range of $16 \mathrm{~Hz}$ to $16 \mathrm{kHz}$ showed the appreciable effect of binder and aggregate used in the mortars. Pumiceous aggregate caused the highest attenuation of the acoustic signal. The natural zeolite seems to be suitable aggregate to NHL and blended lime-cement plasters because it lightens the mortar and positively affects the acoustic attenuation.
\end{abstract}

\section{Introduction}

The coating mortars are used not only as finishing or protecting the walls, but they are developed to satisfy higher and higher technical requirements. The increasing attention for restoration and conservation of historical construction and the elevated environmental sensitivity has re-awakened the interest for lime-based binders. Lime mortars are not suitable for use in the moist environment because of their non-hydraulic properties and low frost resistance. The improvement in material characteristics of lime mortars can be achieved by addition of pozzolanic admixtures or aggregates with pozzolanic properties. Porous pozzolan-active aggregate can be used to prepare lightweight mortars with high ability to salt accumulation from masonry, enhanced strengths and improved their acoustic and thermal insulation properties. The im6provement on acoustic comfort in buildings is commonly achieved through technical solutions involving the application of lightweight and low stiffness materials between the structural slab and the finishing covering [1]. Most often, premixed plasters containing crushed cork as lightweight aggregate are used for this purpose. The use of cork provides a very good performance, due to the high flexibility and resilience of the material [2].

Any detailed study of the acoustic insulation properties of lime mortar with natural lightweight aggregate has not been published yet. Therefore, this study aims to investigate the acoustic insulation properties of fine-grained lime mortars, cement-lime mortars, and

* Corresponding author: vysvaril.m@,fce.vutbr.cz 
natural hydraulic lime mortars using three different natural lightweight aggregate in comparison with mortar with standard quartz sand.

Sound is a mechanical wave of an elastic environment that we perceive through hearing. In solid matter, sound can propagate by longitudinal, flexural, torsional waves or by surface Raigley waves. Periodic changes in the acoustic pressure of real sounds are always more complex than of harmonic sounds and can take various forms from case to case [3]. However, each real waveform can be compiled as a sum of a number of harmonic waveforms with different amplitudes and wavelengths using the Fast Fourier Transform (FFT). Frequency analysis deals with monitoring of the changes in the acoustic pressure level in relation to the frequency. For the purpose of monitoring of the frequency composition of sounds, the audible frequency range can be divided into eleven octave bands, each of which is characterized by its mean frequency $(31.5,63,125,250,500,1000$, 2000,4000 and $8000 \mathrm{~Hz}$ ). Using the octave analysis, technical acoustics can then replace the tedious and detailed FFT [4]. As a result, we obtain eleven (pseudo)tone components, whose wavelength is determined by the middle frequency of the octave and the amplitude. Acoustic spectra provide a good idea of the nature of the sound in regard to the representation of different frequencies in a given sound. In calculations and measurements, only the octave spectrum in the range of 125 to $4000 \mathrm{~Hz}$ is typically used. A sound of a lower frequency than $125 \mathrm{~Hz}$ is perceived by hearing with a low sensitivity. Propagation of sounds of a higher frequency than $4000 \mathrm{~Hz}$ is well attenuated in building materials. If increased accuracy is required, it is possible to get closer to reality by a more detailed division of the spectrum into third-octave, nine-octave, or other special divisions $[5,6]$.

\section{Materials and methodology}

The mortar specimens were prepared using hydrated lime CL 90-S (Carmeuse Czech Republic, Ltd.), natural hydraulic lime (NHL 3.5, Zement- und Kalkwerke Otterbein GmbH \& Co. KG, DE), and CEM I 42.5 R cement (Českomoravský cement, Inc., Mokrá, CZ) as binders; quartz sand (Filtrační písky, Ltd., Chlum u Doks, CZ), natural zeolite (ACRE, Ltd., $\mathrm{CZ}$ ), lava sand (Der Naturstein Garten, Hillscheid, DE), and natural pumice (Der Naturstein Garten, Hillscheid, DE) as fine aggregates $(0 / 2 \mathrm{~mm})$, respectively. Particle size distribution and loose bulk density of the aggregates are shown in Fig. 1. Mortar mixtures were made using the correct amount of water required to obtain a normal consistency and a good workability of the mortars $(160 \pm 5 \mathrm{~mm}$; measured by the flow table test). The proportioning of the mortar mixtures is given in Table 1. The composition of mortar mixtures considers constant binder:aggregate volume ratio of 1:1.15. Fresh mixtures were cast into prismatic moulds of size $40 \times 40 \times 160 \mathrm{~mm}$ and cured at ambient conditions $\left(22 \pm 2{ }^{\circ} \mathrm{C}, \mathrm{RH}=50 \pm 5 \%\right.$.). Bulk density, total porosity measured by mercury intrusion porosimetry (MIP), and acoustic insulation properties of mortars were determined after 28 curing days.

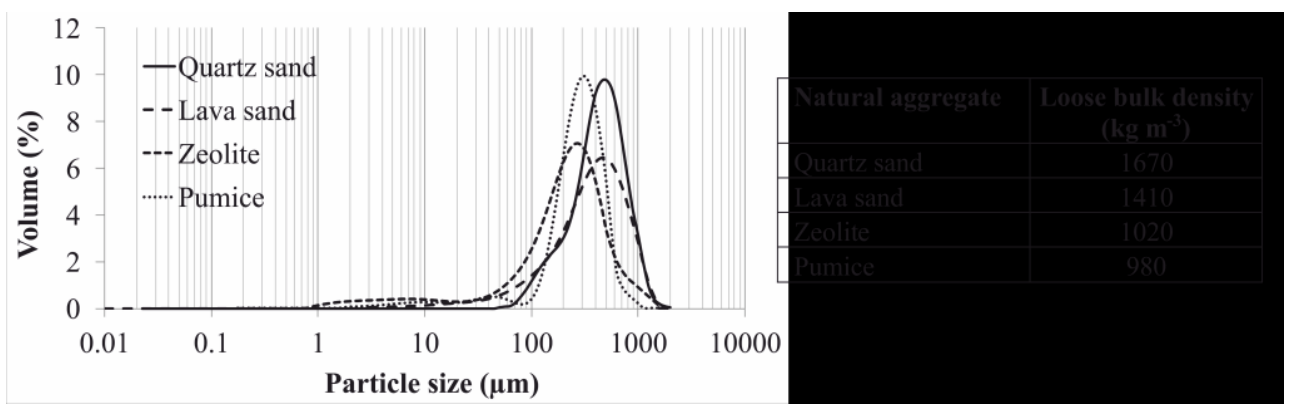

Fig. 1. Particle size distribution and loose bulk density of natural aggregates. 
Table 1. Proportioned mortar mix compositions.

\begin{tabular}{|c|c|c|c|c|c|c|c|c|}
\hline Mixture & Lime (g) & NHL (g) & $\begin{array}{c}\text { Cement } \\
(\mathbf{g})\end{array}$ & $\begin{array}{c}\text { Quartz } \\
\text { sand (g) }\end{array}$ & $\begin{array}{c}\text { Lava } \\
\text { sand (g) }\end{array}$ & $\begin{array}{c}\text { Zeolite } \\
(\mathbf{g})\end{array}$ & $\begin{array}{c}\text { Pumice } \\
(\mathbf{g})\end{array}$ & $\begin{array}{c}\mathbf{H}_{\mathbf{2}} \mathbf{O} \\
(\mathbf{m l})\end{array}$ \\
\hline REF & - & - & 100 & 200 & - & - & - & 50 \\
\hline L-Q & 100 & - & - & 400 & - & - & - & 120 \\
\hline L-L & 100 & - & - & - & 340 & - & - & 115 \\
\hline L-Z & 100 & - & - & - & - & 245 & - & 155 \\
\hline L-P & 100 & - & - & - & - & - & 235 & 135 \\
\hline NHL-Q & - & 100 & - & 340 & - & - & - & 75 \\
\hline NHL-L & - & 100 & - & - & 285 & - & - & 80 \\
\hline NHL-Z & - & 100 & - & - & - & 210 & - & 115 \\
\hline NHL-P & - & 100 & - & - & - & - & 200 & 105 \\
\hline LC-Q & 50 & - & 50 & 280 & - & - & - & 70 \\
\hline LC-L & 50 & - & 50 & - & 240 & - & - & 70 \\
\hline LC-Z & 50 & - & 50 & - & - & 175 & - & 105 \\
\hline LC-P & 50 & - & 50 & - & - & - & 165 & 95 \\
\hline
\end{tabular}

Acoustic insulation properties of mortars were performed by the following methodology. A generator (Agilent 33220A) was used to generate sound waves in the audible frequency range $(16 \mathrm{~Hz}$ to $16 \mathrm{kHz})$. Frequency signal sweeping function (SWEEP) with linear waveform and a total duration of $3 \mathrm{~s}$ and $10 \mathrm{~V}$ amplitude was used. A contact speaker EX60S was used as the source of excitation signal. After the sound passed through the measured specimen, the acoustic signal was captured by a highly sensitive MEMS ADMP401 microphone, converted to an electrical signal and recorded with a digital USB oscilloscope HandyScope HS3. The specimens were stored with acoustic foam pyramid (sound absorption coefficient 0,3 ) in the box, and the measurement took place in the silent laboratory with one operator. The assembled measuring apparatus is shown in Fig. 2. The signal from the time domain was then transferred to the frequency domain using FFT. Subsequently, the amplitude values for the octave spectra in the range 125 to $4000 \mathrm{~Hz}$ were calculated. To properly assess whether the specimen attenuates the selected frequencies, minimum and maximum attenuation values were determined by reference measurements.

Acoustic attenuation in solid materials is defined as energy loss of acoustic wave propagating in medium. This loss of energy can be described in the frequency domain as decrease of amplitude on specific frequency. The attenuation in presented experimental measurements is then mean as a loss of amplitude in frequency spectrum obtained by FFT from recorded signal by MEMS microphone. For the purpose of comparison, attenuation is then represented as a ratio of amplitude at specific frequency regions of test specimen and two boundary reference states [7]. The reference measurement of the minimum attenuation on each frequency was without an inserted specimen. In order to determine the maximum reference attenuation, a reference material was selected - cement mortar CEM I 42.5 R with $\mathrm{w} / \mathrm{c}=0.5$ and quartz sand (REF). Three mortar specimens from each mixture were used to conduct the attenuation test and the averaged results were used to evaluate the acoustic insulation properties of the monitored mortars. 


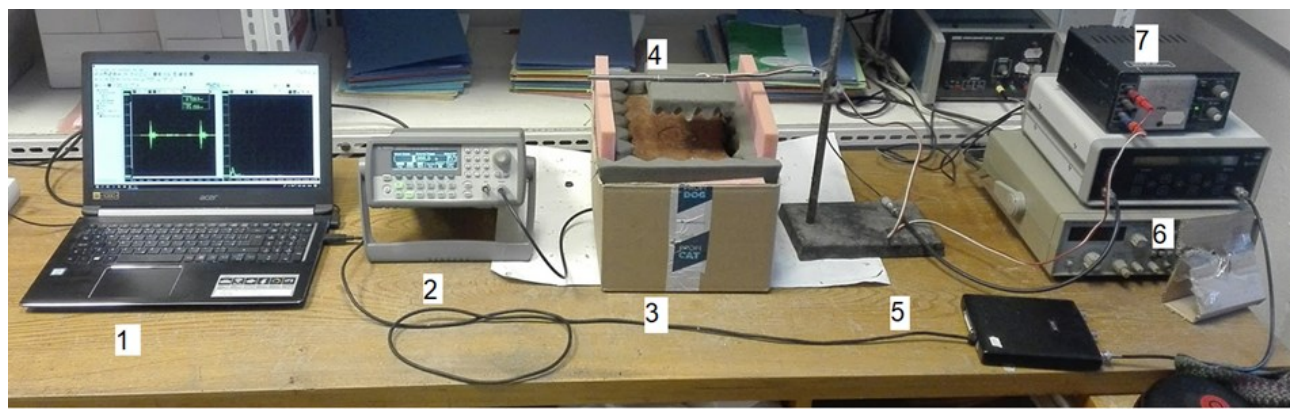

Fig. 2. Measuring apparatus for the SWEEP signal: 1-controlling PC; 2-signal generator; 3-speaker in the bottom of acoustically insulated box; 4-microphone; 5-digital oscilloscope; 6 frequency filter; 7AC source for microphone.

\section{Results and discussion}

The bulk density of mortars decreased according to loose bulk densities of the aggregate (Fig. 3). The total porosity of mortars, determined by MIP (Fig. 4), expectantly increased with decreasing bulk density. The total porosity of the mortars with natural zeolite (-Z) was expected to be higher, considering their bulk densities.

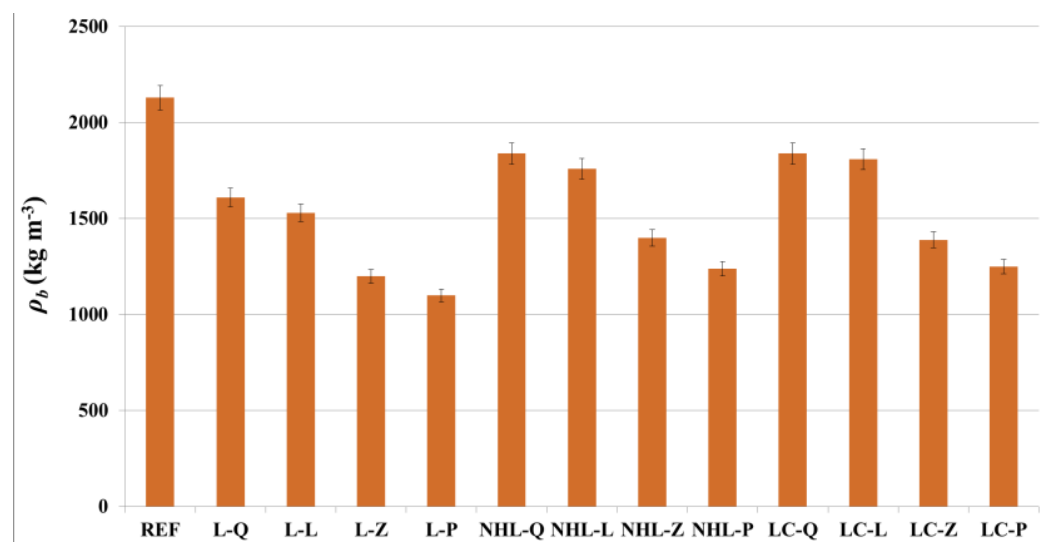

Fig. 3. Bulk density of mortars.

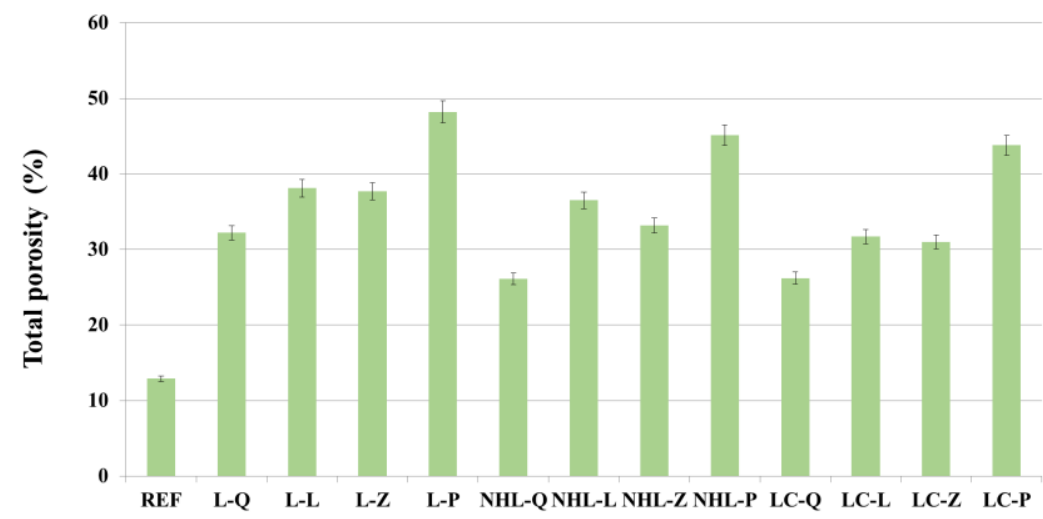

Fig. 4. Total porosity of mortars. 
For the initial determination of the evaluation apparatus (testing the attenuation of acoustic waves), limits for a material with a demonstrably higher attenuation and zero attenuation were determined. These limits are shown in the Fig. 5 in the time and frequency domain. Each test specimen of the individual mixtures was subsequently tested using the above designed apparatus (Fig. 2). In line with the technical-acoustic practice, the responses of the specimens were used to create the octave frequency spectra (quote). Mean amplitude values were created in these frequency domains of each mixture and then they were compared to the marginal conditions for attenuation (the minimum value without the specimen; the maximum value for the REF specimen).
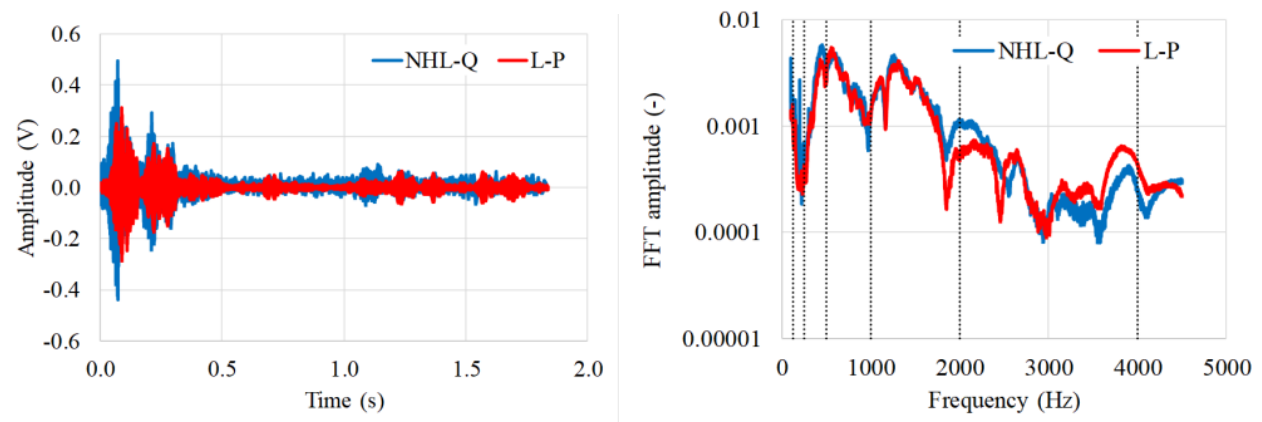

Fig. 5. Comparison of sound waves propagation in the most (L-P) and least (NHL-Q) attenuating mixture (left - time domain, right - frequency domain).

The results for each mixture for selected frequency ranges are presented in Table 2 as a percentage relative to the REF specimen. The value $0 \%$ means no attenuation, $100 \%$ or more represents comparable or higher attenuation than the REF specimen. For better clarity, mixture with a higher attenuation value are highlighted in a dark colour.

Table 2. Attenuation of acoustic waves relative to REF cement mortar (\%).

\begin{tabular}{|c|c|c|c|c|c|c|}
\hline Mixture & $\mathbf{1 2 5}(\mathbf{H z})$ & $\mathbf{2 5 0}(\mathbf{H z})$ & $\mathbf{5 0 0}(\mathbf{H z})$ & $\mathbf{1 0 0 0}(\mathbf{H z})$ & $\mathbf{2 0 0 0}(\mathbf{H z})$ & $\mathbf{4 0 0 0}(\mathbf{H z})$ \\
\hline L-Q & 28.8 & 85.0 & 95.6 & 92.7 & 80.1 & 104.7 \\
\hline L-L & 11.7 & 103.0 & 92.5 & 58.0 & 95.7 & 99.2 \\
\hline L-Z & 49.9 & 84.1 & 83.5 & 58.7 & 94.9 & 105.6 \\
\hline L-P & 18.9 & 101.5 & 97.0 & 59.5 & 107.1 & 92.9 \\
\hline NHL-Q & 0.0 & 65.0 & 87.3 & 60.0 & 66.7 & 108.0 \\
\hline NHL-L & 51.2 & 78.7 & 89.8 & 48.6 & 96.2 & 99.3 \\
\hline NHL-Z & 32.8 & 94.9 & 88.3 & 67.4 & 98.9 & 104.0 \\
\hline NHL-P & 23.2 & 77.3 & 87.6 & 59.3 & 101.5 & 106.9 \\
\hline LC-Q & 0.0 & 54.9 & 87.6 & 70.1 & 91.6 & 101.9 \\
\hline LC-L & 15.1 & 49.1 & 93.1 & 49.7 & 110.5 & 96.4 \\
\hline LC-Z & 1.4 & 89.8 & 83.1 & 49.3 & 97.8 & 111.3 \\
\hline LC-P & 0 & 65.5 & 87.9 & 36.0 & 106.9 & 95.7 \\
\hline
\end{tabular}

The results show that not all the types of lightweight aggregate contribute to better acoustic insulation properties of plasters. From an overall viewpoint, the use of the pumiceous aggregate resulted in the greatest attenuation of acoustic waves compared to the quartz aggregate. The trend of better attenuation in higher frequencies is common for building materials (therefore, frequencies higher than $4000 \mathrm{~Hz}$ are not commonly used in the tests) 
and the results confirmed this statement. Almost all the plaster samples attenuated the highest frequency signals better than the reference cement sample.

When designing the optimum sound absorbing mortar plaster in regard to the physical character of acoustic attenuation in materials, the required result should be highly porous and with a uniform structure that is capable of transforming acoustic wave energy into mechanical and thermal energy [8,9]. Attenuation of acoustic waves can also be achieved by a high bulk density, which will not allow the transmission of the acoustic energy through the structure of the material. When designing composite materials, these two opposing requirements are therefore optimized. It is then difficult to create a high bulk density material which is also highly porous and still has sufficient mechanical properties (internal cohesion). The measured data reveal this result in the L-L and L-P mixtures, which have the highest attenuation of the acoustic signal, correspondingly high porosity, and they are lightweighted.

\section{Conclusions}

The paper presents the acoustic insulation properties of fine-grained lime mortars, cementlime mortars, and natural hydraulic lime mortars using three different natural lightweight aggregate in comparison with mortar with standard quartz sand. Through the study, the following conclusions can be drawn: All lightweight aggregates reduce the bulk density of mortar and increase their total porosity in accordance with their decreasing loose bulk density. From an overall viewpoint, the use of the pumiceous aggregate results in the greatest attenuation of acoustic waves compared to the quartz aggregate, it considerably increases the total porosity of mortar, and dramatically lightens the mortar. The natural zeolite seems to be suitable aggregate to NHL and blended lime-cement plasters because it lightens the mortar and positively affects their acoustic attenuation.

This work has been financially supported by The Czech Science Foundation (GA CR) project No. 18-07332S and by Ministry of Education, Youth and Sports under the „National Sustainability Programme I“ - the project No. LO1408 „AdMaS UP - Advanced Materials, Structures and Technologies“.

\section{References}

1. K. Kyoung-Woo, J. Gab-Cheol, Y. Kwan-Seop, S. Jang-yeul. Build. Environ. 44, 1589-1600 (2009)

2. F.G. Branco, L. Godinho, Constr. Build. Mater. 45, 184-191 (2013)

3. M.N. Khan, S. Panigrahi, Principles of engineering physics (Cambridge University Press, New York, 2016)

4. H.S. Hens, Building physics-heat, air and moisture: fundamentals and engineering methods with examples and exercises (John Wiley \& Sons, 2017)

5. Z. Li, M.J. Crocker, Int. J. Acoust. Vib. 10, 159-169 (2005)

6. L. Brancher, M. Nunes, A. Grisa, D. Pagnussat, M. Zeni, Materials 9, (2016)

7. M. Schickert, M. Krause, W. Müller. J. Mater. Civ. Eng. 15, 235-246 (2003)

8. H. Estrada, P. Candelas, A. Uris, F. Belmar, F.J. García de Abajo, F. Meseguer, Phys. Rev. Lett. 101, 084302 (2008)

9. M. Juřička, M. Vašina, L. Lapčík, ICSV 13, 352-359 (2006) 